\title{
Enlivening the Classroom: Some Activities for Motivating Students in the Course History of English Literature
}

\author{
Nguyen Ho Phuong Chi ${ }^{1}$ \\ ${ }^{1}$ Department of English, Ho Chi Minh City University of Education, Vietnam \\ Correspondence: Nguyen Ho Phuong Chi, Department of English, Ho Chi Minh City University of Education, \\ Vietnam. Tel: 84-8-22431389. E-mail: chinhp@hcmup.edu.vn
}

Received: January 8, 2013 Accepted: January 23, 2013 Online Published: January 29, 2013

doi:10.5539/ells.v3n1p67 URL: http://dx.doi.org/10.5539/ells.v3n1p67

\begin{abstract}
With the introduction of the credit-based education in Vietnamese higher education, teachers are expected to spend more time to familiarize themselves with the new system at the start. They also need to be adaptable and resourceful to accommodate their students' arising needs and institutional changes. This paper outlines one teacher's attempt to motivate students' learning in the course History of English Literature through the employment of Cottrell's CREAM framework in the context of credit-based learning arrival. Students' feedback shows that they are highly engaged in the lesson and feel more interested in reading as well as writing by joining various activities organized by the teacher. As a result, their study has become more creative, reflective, effective, active and motivated. It is implied that teachers can make use of the CREAM strategy for designing other meaningful activities to motivate their students to learn other subjects.
\end{abstract}

Keywords: classroom activities, CREAM strategy, credit-based education, teaching History of English Literature

\section{Introduction}

At present, Vietnam is striving hard for a comprehensive educational overhaul in which English language teacher training program is experiencing significant influences as the Vietnamese Ministry of Education and Training (MOET) tries to implement new policies and plans. Crucial changes happening in the higher education system in Vietnam can be listed as (1) MOET's endeavor to establish a national standard framework for English teacher education curriculum in 2010, (2) its attempt to implement the credit-based system into the training programs of Vietnamese institutions since the early 1990s, (3) its plan to implement the national foreign language project Teaching and Learning Foreign Languages in the National Formal Educational System in the Period of 2008 -2020 and (4) each individual institution's struggle to improve its own curriculum based on MOET's emerging policy. However, in this context of major changes, few studies have detailed individual English teacher's attempts to incorporate new teaching approaches to motivate their students' learning. As an English lecturer, I myself feel the urgent need to look for innovative methods and techniques so as to adapt my teaching in order to meet the requirements set out by the Department, the institution and MOET. In this paper, I am going to share some activities I carried out in the course History of English Literature with a view to engaging my students to this subject, which has traditionally been deemed boring.

\section{The Teaching of Literature at the English Department, Ho Chi Minh City University of Education}

Ho Chi Minh City University of Education is a specialized teacher training institution in Vietnam. Through its diverse teacher education programs, the university seeks to train qualified teachers to supply teachers with Bachelor degrees for a variety of schools from kindergarten to primary, secondary and high school for the South of Vietnam and also for the whole country. In response to MOET's call for the implementation of credit-based education at higher education (Minister of Education and Training's Decision No. 43/2007/QD-BGDDT, 2007), Ho Chi Minh City University of Educationhas adopted the credit-based education since 2010. It is expected that the transition to a credit-based education in Vietnam would foster learner autonomy because under the credit-based system, students must be responsible for their own learning by selecting the course, creating their study planning and spending time learning independently.

The English Department is one of the 21 Academic Faculties at Ho Chi Minh City University of Education. It 
currently offers three mainstream English education programs leading to two degrees, namely Bachelor of Arts (Teaching English) and Bachelor of Arts (Business English). The course History of English Literature, along with English Literature, American Literature and Intercultural Communication, falls directly into the responsibility of the Division of Literature-Culture. Before the academic year 2010, it was a compulsory subject for all second year students. With the introduction of the credit-based system in 2010, it has been listed as an elective course for first year students of Business English and compulsory subject for second year students of English teacher education. At the English Department in general and within the Division of Literature-Culture in particular, although teacher attitudes toward the implementation of the credit-based education are more positive than negative, progress has been slower than expected because of significant teacher reluctance. Hence, in these very first years of credit-based education implementation, lecturers are strongly encouraged to experiment and share with one another new teaching techniques and ideas so as to provide a better base for the successful application of this new system. For lecturers, with the credit-based system implementation, they often feel more stressed with new changes in the classroom. In terms of time, each period now lasts 50 minutes instead of the traditional 45-minute class. The assessment also converts from 10-point scale to 5-point scale system with two decimal numbers instead of round number. More student-centered activities are encouraged in class. As such, lecturers and students preparations are crucial for the success of a teaching period in the new system.

\section{Design of Activities}

\subsection{Rationale for Designing Activities}

\subsubsection{Course Objectives}

It is clearly stated in the outline of the course History of English Literature that "By the end of the course, students are expected to grasp the basic knowledge on the culture and society that embraces English literature for the period from the Anglo-Saxon ages to the modern times". Further to this main objective, the course puts a strong emphasis on the $16^{\text {th }}$ century, which is described as "the flowering of English Literature" and the $20^{\text {th }}$ and $21^{\text {st }}$ century, which have witnessed the emergence of key Nobel Prize winners. Therefore, much time is spent on helping students to absorb key social events as well as writers belonging to these two literary periods. The main concern in delivering this course is assisting students in broadening their understanding of English language by integrating context into Literature and English Language because this course provides background knowledge essential for upcoming courses such as English Literature and American Literature.

The current textbook for the course is a combination of compiled texts about various literary periods from the Modern Times back to Anglo Saxon ages selected by the Head of the Division after discussion with responsible lecturers and getting approval from the Department Academic Board. The contents are presented in reverse chronological order because students are expected to learn the most recent literature and history before exploring old written English and culture. Apart from the textbook, all the course instructorswere strongly encouraged by the Head of the Division as well as the Dean to select and try out any materials supported their teaching.

\subsubsection{Students' Needs}

Previous classroom observations and teachings have brought to my mind several important questions related to delivering the course History of English Literature such as"Why do many students dislike reading the materials at home?"“Why are they so passive whenever a question is raised?"'Why are they just trying to copy as many words as they can while the lecturer is talking?"“Why is the attendance rate in Literature class so low?"“What can be done to make Literature course more appealing?"

I asked 120 students in three classes to complete the End-of-course surveyon the effectiveness of the course History of English Literature in 2009, the year immediately before our English Department rewrote the whole syllabus for all the courses for the implementation of the credit-based system. The purpose of this survey is to gain evidence for reconstructing the course. Issues concerning the course noted by students could be summarized as:long materials, separate readings of History and Literature, too many facts and figures mentioned in each literary period, little focus on key literary figures, few illustrated examples of masterpieces, few explanations or clarifications on culture, society and how they shape the development of literary traditions, heavy burden on the written test for final assessment which requires students to review all the stories and authors they have been introduced to throughout the course.

Students' responses to the course evaluation, together with the researcher's observation notes were brought to discussion in the staff meeting dealing with the reconstruction of new syllabus for the course History of English Literature at the Division of Literature-Culture, Department of English, Ho Chi Minh City University of Education. All the lecturers at the Division of Literature-Culture agreed that new teaching approaches should be 
encouraged to the delivery of the course so as to reflect both institutional changes and students' needs. Ideas and strategies for delivering the course were, therefore, highly appreciated.

\section{Frameworks for Designing Activities: CREAM Strategy for Learning}

Using an acronym CREAM, Cottrel (2003: 55) recommends five strategies which seeks to empower students with essential learning skills:

C-Creative: Have the confidence to use individual strategies and styles, applying imagination to learning

R-Reflective: Be able to sit with one's own experience, analyze and evaluate one's own performance, and draw lessons from it

E-Effective: Organize space, time, priorities, state of mind and resources (including Information Technology, IT), to the maximum benefit

A-Active: Be personally involved and doing things, physically and mentally, in order to make sense of what you learn

M-Motivated: Be aware of one's own desired outcomes; keep oneself on track using short and long-term goals

Cottrel (2003) further explains that each individual strategy in the CREAM framework is in a dependent relationship with each other. For instance, being active fosters learning motivation and interest. Being interested and motivated requires reflection and making sense of your experience.

The CREAM learning strategies have been applied in the Vietnamese context of teaching and learning English with Truc's study in 2010 carried out on 48 freshmen of English majored trained to become English teachers at primary and lower secondary school at Thua Thien Hue College of Education, Hue City, Vietnam (Truc, 2010). Drawing on four out of five techniques in the CREAM model, Truc built up four activities with a view to familiarizing her students with the transition from high school to college. Her project has proved to be successful with students' positive feedback on the establishment of four activities, including: study plans, fields trips, letter exchanges and self-evaluation. According to Truc (2010), these activities were not part of the curriculum and students' participation was not formally graded. Although it is true that these activities were designed to help students become independent and active learners, a key to success in the credit-based education, all of them were tasks outside classroom hours. The activities mentioned also lack the depth, breadth and concrete examples regarding the uniqueness of the teaching of English for English majors students because students in other disciplines can also depend on study plans, fields trips, letter exchanges and self-evaluation for better learning achievement.

As a result, the implementation of the CREAM framework for enhancing teaching and learning effectiveness in the context of credit-based education in Vietnam still requires more studies with detailed focus on subject-specific teaching approaches. I have decided to build up activities based on the CREAM framework for my students in the course History of English Literatureat the beginning of the shift from academic year system to credit-based education. The activities discussed are very lesson-specific andcould be used for the teaching of subjects related to English Literature.

\section{Descriptions of Activities}

\subsection{Activity 1: Creative Poem Writing}

This activity employs the C (Creative) strategy for learning. According to Cottrel (2003: 55), students need to apply imagination to their learning. When learning Literature, it is important that students have the opportunity to compose their own writing to make the imagination fly high. This is one example of how students can develop their writing skills based on working with poems.The poem "Stufferation" by English poet Adrian Mitchell is selected for reading and then students are asked to do the tasks: comment on the structure of the poem and think of any stuff then create writing in the same format: Description - Name - I like that stuff/ I hate that stuff

Lovers lie around in it

Broken glass is found in it

Grass

I like that stuff

Tuna fish get trapped in it

Legs come wrapped in it 
Nylon

I like that stuff

Eskimos and tramps chew it

Madame Tussaud gave status to it

Wax

I like that stuff

Elephants get sprayed with it

Scotch is made with it

Water

I like that stuff

Clergy are dumbfounded by it

Bones are surrounded by it

Flesh

I like that stuff

Harps are strung with it

Mattresses are sprung with it

Wires

I like that stuff

Carpenters make cots of it

Undertakers use lots of it

Wood

I like that stuff

Cigarettes are lit by it

Pensioners are happy when they sit by it

Fire

I like that stuff

Dankworth's alto is made of it, most of it,

Scoobeedo is composed of it

Plastic

I like that stuff

Apemen take it to make them hairier

I ate a ton of it in Bulgaria

Yoghurt

I like that stuff

Man-made fibres and raw materials 
Old rolled gold and breakfast cereals

Platinum linoleum

I like that stuff

Skin on my hands

Hair on my head

Toenails on my feet

And linen on my bed

Well I like that stuff

Yes I like that stuff

The earth

Is made of earth

And I like that stuff

Students particularly found this activity motivating. A few minutes were spent on clarifying new concepts mentioned in the poem such as Madame Tussaud or Scoobeedo. Later studentswere asked to compose their own stanza based on the poem's format of "Description - Name - I like that stuff/ I hate that stuff" and then shared with their friends. The class became so noisy during students exchange of poems. Some students volunteered to write down their creative writing on the board. They described in words almost all the things possible while the rest of the class tried to guess the stuff or concept their mates were referring to. Students believed they felt really warmed up with this kind of activity "very engaging, but incorporating learning poetry with writing skills". Students even thought of very abstract concepts or tricky puzzles. The whole class voted for the best stanza of the day and bonus marks were given to students with highest votes.

Here are some examples of students' stanzas:

"Life is born with it

Death returns to it

Dust

I hate that stuff"

"Rose is a sign of it

Kisses are common of it

Love

I like that stuff"

"The rich needs it

The poor has it

Eat it and you 'll die

Nothing

I hate that stuff"

In this activity, the lecturer used a poem to motivate the study of poetry itself. It is known as "reproducing the model" by adaptation and as Stern (1991: 333) points out this technique enables students to use experiment the 
language and be aware of the variations between written and spoken English. Moreover, when composing their own stanzas, students got more chance to understand about the usage of written English for poetry in terms of grammar, syntax and vocabulary. They were also exposed to tremendous use of figures of speech. This activity shows many advantages of using poetry in class, as Sage (1987: 12-13) describes: employing language to evoke and exalt special features of life, communicating feelings with readers, representing cultural elements such as allusions, vocabulary, idioms and tone.

\subsection{Activity 2: Learning Portfolio Creation with Critical Reflection Notes}

This activity makes use of the $\mathrm{R}$ (Reflective) strategy for learning. In fact, there are five methods for developing reflection listed by Cottrell (2003), namely: keeping a learning journal, using evaluation sheets, creating an updated profile, making constructive use of feedback and frequently filling in progress sheets. This activity was created to help students learn the novel of the Victorian age. Students were expected to build up their learning portfolios and keep reflection notes. At the end of the course, students submitted their group's portfolios with reflection notes from each member. Below is the detailed description of how the activity was delivered to introduce students to Victorian novels.

First, it is worth mentioning that short story is the dominant genre explored in most Literature course at the English Department because of its values such as: easier reading tasks, more worldviews about different cultures and groups, more personal explorations and universal themes as well as developing students' cognitive power (Sage, 1987: 43). However, students claimed that they would love to know more about longer masterpieces written in the form of novel. The Victorian age, the time when novel flourished, brought the great choice. Therefore, a book advertisement project was created with a view to showcasing students the literary accomplishments of the age. Students were required to work in group of four to complete this assignment.

Novel was selected instead of short story because this literary genre dominated the Victorian age and students hardly had the chance to work with long texts throughout their study. Moreover, researchers like Custodio \& Sutton (1998: 19) and McKay (1992: 53) have highlighted some educational benefits of using novel in a foreign language class such as:fostering students' overall reading proficiency, stimulating students' imagination, connecting the characters' lives with their own problems and situations, developing the skills of gathering information and arriving at meaningful decisions, enhancing students' language skills, combining between comprehension and analytical activities, motivating the task of reading, motivating life-long reading habit among students.

Victorian novels were selected for students' project based on their popularity. On the exhibition day, the class turned into a book fair, with stands decorating to reflect the themes in the book. Each group had ten minutes to introduce their story and five minutes for audience inquiry. Some students even dressed up like the characters' in the stories. Long and well-known novels such as Alice in the Wonderland, Jane Eyre, Pride and Prejudice, and Wuthering Heights were beautifully presented, especially when students linked its appealing power with the current youth reading taste. For instance, the eternal love story between Heathcliff and Catherine in Emily Bronte's Wuthering Heights seemed to be questioned in today's world when one group of students introduced the novel to the whole class in a form of a TV program called "Today's Book". In another situation, the whole class was amazed at the sight of the "crazy" animals in very strange "custom" when one group demonstrated the characters of Cheshire Cat, Rabbit and Hat Maker in Alice in the Wonderland. Storms of surprise and excitement made the class show more successful when the story Jane Eyre was presented digitally through students' careful preparation. In addition, for all the stories introduced, each group needed to add expression of their own feelings upon endings of novels or their own reflections on the intriguing details of the story such as "announcing their own definition of love", "lamenting on the loss of one's pride " or "forgetting one's prejudice" and so on.

This kind of project also promoted students' collaboration. They needed to share ideas and exchanges resources with their peers to complete the project. It also involved high-level thinking ability, as it required students to give their own comments on the story. Moreover, a great number of books were introduced to the class in a limited time. Students believed that they got a glimpse of each book during the show and many of them looked for the further reading out of class time. This, in fact, has contributed to developing students' reading habit in English. In order to guarantee the success of this activity, the lecturer should recommend the books that are suitable for students' level and interest. Students need to work with their peers about two to four weeks for a ten-minute in-class presentation and much time would be required if more in-depth analysis or critical questions about the story are to be asked.

\subsection{Activity 3: Learning Logs}

This activity uses the E (Effective) strategy for learning. Cottrell (2003: 55) emphasizes the quality of being 
organized in effective learners. She insists that learners need to develop the skills of managing time, space, priorities and resources to guarantee their successful learning. In this case, students were provided with the opportunity to keep their learning logs via the use of the Internet. A Facebook page about the course was created and students who got Facebook accounts were invited to join the page to post their comments as well as their concerns in the course. In addition, students also shared the links about the books that were discussed in the class. The lecturer managed this Facebook account and kept communication with students via this social network exchange. Students felt very motivated to speak out their thoughts on the course Facebook page because they considered the widespread popularity of Facebook and the easy managing search of common books available on this online tool. One student emphasized that this activity was "captivating because it linked study with up-to-date technology. We could expand our knowledge about books, novels, poems by just some simple clicks. More importantly, we are kept in touch with other friends and readers from far-away corners." Although this activity was highly recommended to the students, I did not mark them for their participation. The reason was that I wanted to keep my students and myself up with the social trends but students' use of Facebook was concerned with a lot of out-of-class stuff and there seemed to be no suitable criteria for grading them. Moreover, to help students keep track of their learning and Facebook use of the course, a learning log was sent to their email each week before the date of class and students were asked to complete the log. This learning log was designed based on Donna Ogle's K-W-L chart for reading comprehension enhancement strategies (Ogle, 1986). The K stands for students' prior knowledge, the $\mathrm{W}$ means what students want to learn and L stands for students' actual learning achievement. According to Carr \& Ogle (1987), KWL charts assist students in reading by giving them specific things to look for and opportunities to reflect. The KWL in this context was slightly adapted with components based on students' lesson and the online communication via email and Facebook. Therefore, the KW parts of the $\log$ were to be completed before the lesson started while the L section was done after the lesson finished. Students' feedback on this activity showed that having the learning log helped them to focus on their learning expectations, motivating them to achieve the learning outcomes as well as making their study organized and manageable.

\subsection{Activity 4: Library Visit}

This activity is built upon the A (Active) strategy for learning. To become active learners, students need to make sense of what they learn by engaging themselves in doing things physically and mentally (Cottrell, 2003: 55). The lecturer designed this activity to promote students reading habit of written texts and it was carried out from the beginning to the end of the course. Students of the English Department had access to two libraries in our institution: the University Library with books in different disciplines written in Vietnamese and the Department Library with books in the field of teaching English and English Literature written in English. Students were asked to visit either the University Library or English Department Library or both and kept a written record of what they had borrowed at each Library. After that, they wrote one short paragraph about anything memorable of each book. All their notes about library visits and books were collected at the end of the course. The lecturer used them as a guide to explore about students' common borrowing books and their expressions about each of the book they read. Students' written notes were not marked. However, students said that they acquired the habit of visiting the library and developed the searching ability of library catalogue. A majority of students thought that this activity would be more beneficial if they could create their own library catalogue of favorite books and then combine it with that of their friends to make a list of their own class' recommended books. This list could be then shared with other classes and extend to the whole Department. Students also suggested establishing a Book Club for students in the Department.

\subsection{Activity 5: Poetry Learning and Culture Exploration}

This activity employs the M (Motivated) strategy for learning. Cottrell (2003: 59) claims that being motivated means being aware of your own desired outcomes and being able to keep track of your short and long-term goals. For my students, they needed to be motivated to grasp the difficult social concepts. Following is an example of the use of poetry to promote students' cultural understanding.

When learning about the social background of the twentieth century in England, "the swinging sixties" was among many key ideas that students considered very hard to comprehend. Fortunately, I found a poem that explicitly depicts England in the Swinging Sixties. Therefore, the lesson about the historical background of this time became a poetry discussion of "Annus Mirabillis" by Philip Larkin:

\section{Sexual intercourse began}

In nineteen sixty-three 
(which was rather late for me) -

Between the end of the "Chatterley" ban

And the Beatles' first LP.

Up to then there'd only been

A sort of bargaining,

A wrangle for the ring,

A shame that started at sixteen

And spread to everything.

Then all at once the quarrel sank:

Everyone felt the same,

And every life became

A brilliant breaking of the bank,

A quite unlosable game.

So life was never better than

In nineteen sixty-three

(Though just too late for me) -

Between the end of the "Chatterley" ban

And the Beatles' first LP.

Roars of laughter and confusion were noticed when the poem first read, especially with the beginning words "sexual intercourse". However, questions following the poem triggered students' thought:

- Which year witnessed a great number of changes?

- Which events are mentioned?

- How well have you known about the Beatles? and Chatterley?

- What kind of feeling do you think that the author is experiencing?

- What is the relationship between "sexual intercourse", "the ring", "sixteen", "the quarrel" and "game"?

When my students worked on the answers to those questions, they had almost uncovered the history as well as the society norms and expectations of a world miles away from their homeland. This poem was effectively useful for introducing the key social events of England in the 1960s. In addition to gaining a better understanding of new concepts like "sexual freedom" and "popular culture", students got the chance to analyze the rhyming scheme when reading Annus Mirabillis.

\section{Evaluation of Activities}

\subsection{Lecturer's Reflection on the Use of these Activities}

After conducting these activities in the classroom for one academic year, I find that I have created a very rich source of portfolios for my teaching and my students' learning. Students' products including pictures, short movie clips, notes, worksheets, learning logs, etc. are all kept by class and then I add my own comments on how well they have worked with each activity. These materials are then shared with all the lecturers in the Division and the Department. A bank of teaching resources was effectively created especially for the teaching of Literature subjects. In addition, I feel relaxed when working with my students because I know that with the employment of the above activities, my students are going to work hard as much as I prepare my lesson. I am more motivated to read and immersed myself in modern English Literature to search suitable poems and stories for my students. I have created a list of "manageable" texts of contemporary English writers, which could be used to build up interesting classroom activities based on CREAM strategy such as the poem Men Talk by Liz 
Lochead, My Grandmother by Jackie Kay, Nice Neighborhood Great Country by Roger McGough, the short story My Father by Doris Lessing, the play Pygmalion by George Bernard Shaw.

The implementation of these activities will heavily depend on the classroom environment. I am lucky to see the smooth flow of the classroom procedure during my first time of employing these tasks because the proficiency of my students are quite good, with almost all students reaching the level of High Intermediate. Another thing worth mentioning is that a high level of cooperation had been achieved between the students and lecturer as well as between students. Moreover, though not always necessary, the use multimedia rooms well equipped with computers, LCD projectors, and sound systems are desirable for the smooth operation of some of the above activities, especially for displaying the poems. However, within limited resources available, the lecturer can still apply these activities by preparing handouts and copy materials in advance. These activities are, therefore, could run well with large class with no access to modern language teaching facilities. Furthermore, when working with these activities, lecturers need to consider issues relating to classroom management and time constraints because time for explaining and settling students may influence time for delivering main points of the lesson.

\subsection{Students' Perceptions on the Effectiveness of these Activities}

Semi-structured interviews were conducted with 6 purposively selected students from three classes. One student with high achievement in previous semester and one with lower record from each class were invited to speak out their feelings for the activities carried out through the course in about 30 minutes. The interviews were done after they completed the final examination. It is to be made clear that they were no longer in the dependency relationship with the lecturer and nor would they be for the remainder of their training at the institution because the lecturer finished all her teaching and was to go abroad for a long-term study after that semester. Therefore, students were encouraged to share as much as they could while the lecturer took notes during each of the interview. Emerging themes arising from students' experience could be summarized as:

First of all, when being asked to rate the effectiveness of these activities in motivating their learning, six students believed that they were "extremely effective". They claimed that the CREAM objectives of creative, reflective, effective, active and motivated were explicit in almost every aspect of each activity. They were quite satisfied with their performance and engagement in the course this semester.

Secondly, six of the interviewed students enjoyed all the activities because they motivated them to work collaboratively. Group work is crucial to their success as well as comprehension of the poem, novel or story. Therefore, students could spend more time learning and cooperating with each other. This has clearly created a valuable opportunity for them to discuss, share and evaluate other's work. Four of them think this is the key change in the study of "Literature" subject, which was previously viewed as valuing individual expression to group contribution. All of them believe that working in groups reduces the burden of preparation and writing as conventionally required in a literary course while maximizing various angles of critical analysis and interpretations.

According to those interviewed, another value of working on these activities is that they were encouraged to give the written responses without fearing of "right or wrong answer" because the requirement in each of the activity was very case-specific and the lecturer had always reminded them that "No absolute right or wrong answer, it is your justifications that count". The student who got the highest grade for the course felt that "I used to think learning Literature and History of English Literature would be a waste of time for us, especially when we are trained to become teachers of English skills but the course is beyond our expectations. I am exposed to new interesting activities that could be used for our future teaching. I have sharpened my reading ability, critical thinking skill. In a word, this is an advanced reading and advanced writing class with so much fun and exciting journey into the English world. I even fall in love with the English culture and I wish I could come to England some day to further my study, to explore the country and to fulfill my personal desire of using authentic English with the native people there."

\section{Conclusion}

In brief, this paper gives a description of the activities carried out in a classroom. They were designed and employed at the advent of credit-based education at the English Department, Ho Chi Minh City University of Education. In theory, the syllabus for the subject History of English Literature has been completed but in practice the course construction is still underway. Similarly, the implementation of credit-based education in Vietnamese higher education system is still a progressive process with continuous adjustments. That is why each lecturer in charge of the subject is encouraged to experiment and carry out new teaching techniques so as to provide more evidence for perfecting the syllabus and curriculum. Initial students' feedback about the implementation of these activities is positive. However, for the successful reduplication of these activities in other contexts, several issues 
need to be considered such as students' English proficiency, lecturer's prior experience in English culture and Literature teaching as well as institutional support. More qualitative or quantitative results are also needed for the wider use of these activities in other EFL context.

\section{References}

Carr, E., \& Ogle, D. (1987). K-W-L Plus: A Strategy for Comprehension and Summarization. Journal of Reading, $30,626-631$.

Cottrell, S. (2003). The Study Skills Handbook (3rd ed.). New York: Palgrave Macmillan.

Custodio, B., \& Sutton, M/J. (1998). Literary-Based ESL for Secondary School Students. TESOL Journal, 19-23.

Mason, T., Arnove, R., \& Sutton, M. (2001). Credits, Curriculum, and Control in Higher Education: Cross-National Perspectives. Higher Education Studies, 42(1), 107-137. http://dx.doi.org/10.1023/A:1017525003769

McKay, S. (1982). Literature in the ESL Classroom. TESOL Quarterly, 16(4), 429-536. http://dx.doi.org/10.2307/3586470

Minister of Education and Training's Decision No. 43/2007/QD-BGDDT. (2007). Quy chế đào tạo theo tín chí. [Regulation on higher education training under the credit system]. Ha Noi.

Ogle, D. (1986). K-W-L: A teaching model that develops active reading of expository text. The Reading Teacher, 39, 564-571. http://dx.doi.org/10.1598/RT.39.6.11

Regel, O. (1992). The Academic Credit System in Higher Education: Effective and Relevance in Developing Countries. Washington DC: World Bank.

Sage, H. (1987). Incorporating Literature in ESL Instruction. New Jersey: Prentice-Hall, Inc.

Stern, S. (1991). An Integrated Approach to Literature in ESL/ EFL in Teaching English as a Second or Foreign Language. Boston: Heinle \& Heinle Publishers.

Truc, L. T. T. (2010). Enhancing Students' Performance in ELT Programs in the Credit-Based Training System. Language Education in Asia, 1, 133-14. http://dx.doi.org/10.5746/LEiA/10/V1/A12/Le 